\title{
Sugammadex in end-stage renal disease: too early for a "free-pass"
}

\author{
Rohan Magoon, DM, MD (D) Ramesh Kashav, MD • Jasvinder Kaur Kohli, MD
}

Received: 18 October 2020/Revised: 20 October 2020/ Accepted: 21 October 2020/Published online: 16 November 2020

(C) Canadian Anesthesiologists' Society 2020

\section{To the Editor,}

We read with interest the retrospective study by Paredes et al. evaluating the outcomes in an end-stage renal disease (ESRD) cohort receiving sugammadex $(\mathrm{SGX}){ }^{1}$ The outcomes (complications) they evaluated need further comment and clarification.

The authors included hypersensitivity reactions, reintubation, hypoxemia, and pneumonia as the primary postoperative complications. ${ }^{1}$ Nevertheless, they did not consider other well-recognized drug-related cardiac adverse effects such as bradycardia, particularly relevant in ESRD settings prone to hyperkalemia-induced conduction disturbances. ${ }^{2,3}$ In addition, reports of thirddegree heart block, asystole, hypotension, coronary vasospasm, and cardiac arrest with SGX also warrant caution. $^{2}$

While the primary complications (which manifest in 18 of their 219 patients) were stated to be unrelated to SGX, this finding needs to be carefully interpreted given the inability to rule out SGX as a contributing factor in a third $(6 / 18)$ of the patients. Despite the explanation put forth in support of there being little significance to the neuromuscular blocking agent (NMBA) dissociation from

This letter is accompanied by a reply. Please see Can J Anesth 2021; this issue.

R. Magoon, DM, MD $(\bowtie) \cdot$ R. Kashav, MD · J. K. Kohli, MD Department of Cardiac Anaesthesia, Atal Bihari Vajpayee Institute of Medical Sciences (ABVIMS) and Dr. Ram Manohar Lohia Hospital, Baba Kharak Singh Marg, New Delhi, India e-mail: rohanmagoon21@gmail.com the prolonged exposure to SGX-NMBA complexes in ESRD, the authors cannot completely exclude the possibility of residual neuromuscular blockade in the absence of universal quantitative neuromuscular monitoring, particularly across the range of SGX doses employed. ${ }^{1,4}$ Moreover, circulatory shock (highlighted as a cause of primary complication) can itself hamper the SGXNMBA complex clearance. In addition, their citation of volume-overload as the cause of postoperative hypoxemia is also far from objective.

Lastly, comparing their original cohort with a control group that had received neostigmine would have been a better method to account for the SGX-associated complications. Although the authors need to be commended for their study to potentially allow a more expansive role of SGX, issuing a "free-pass" to SGX in ESRD without more robust prospective data may have its own problems.

Disclosures None.

Funding statement None.

Editorial responsibility This submission was handled by Dr. Hilary P. Grocott, Editor-in-Chief, Canadian Journal of Anesthesia.

\section{References}

1. Paredes $S$, Porter SB, Porter IE 2nd, Renew JR. Sugammadex use in patients with end-stage renal disease: a historical cohort study. Can J Anesth 2020; DOI: https://doi.org/10.1007/s12630-02001812-3.

2. Kapoor MC. Cardiovascular adverse effects of sugammadex. J Anaesthesiol Clin Pharmacol 2020; DOI: https://doi.org/10.4103/ joacp.JOACP_132_20. 
3. Farkas JD, Long B, Koyfman A, Menson K. BRASH syndrome: bradycardia, renal failure, AV blockade, shock, and hyperkalemia. J Emerg Med 2020; 59: 216-23.

4. Naguib M, Brull SJ, Kopman AF, et al. Consensus statement on perioperative use of neuromuscular monitoring. Anesth Analg 2018; 127: 71-80.
Publisher's Note Springer Nature remains neutral with regard to jurisdictional claims in published maps and institutional affiliations. 